\title{
The Meaningful Integration of Emerging Learning Technologies
}

\author{
John H. Curry ${ }^{1}$ - Pamela J. Ponners ${ }^{2}$ \\ Published online: 29 December 2018 \\ (C) Association for Educational Communications \& Technology 2018
}

Over the nearly quarter century of AECT membership and service we, the guest editors, have had, our division has had many names. The first we remember is the Multimedia Design and Production division. From there, the division was rebranded and renamed the Multimedia Production division. However, over the course of the years, this name has not truly captured the essence of the research and practice of our division membership. No longer was the division a group of people spending their time in a back office coding all day long. We had developed into a group of researchers and practitioners working together to examine new technologies and explore their potential uses and integration into the learning process. The division leadership and membership worked together to identify a name that captured who we are today. In December of 2015, the AECT Board of Directors approved our division name change from the Multimedia Production Division to the Division of Emerging Learning Technologies (DELT). It was a big moment for all of us who had been involved in the process. From there we set out to help others better understand who we are as a division and what we are all about. The newly approved mission of the division "is to promote the discovery, experimentation, production, and utilization of emerging technology tools and practices" (Division of Emerging Learning Technologies bylaws). Sponsoring this special issue of TechTrends is the culminating activity of our rebranding process.

We were pleased so many answered the call for papers for this issue. The task to review all the proposals and invite full papers was not any easy one. There were so many great ideas proposed - each of which corresponded to and highlighted a

John H. Curry

j.curry@moreheadstate.edu

Pamela J. Ponners

Pamela.Ponners@gmail.com

Morehead State University, Morehead, KY, USA

2 UT Southwestern Medical Center, 5323 Harry Hines Blvd, Dallas, TX 75390, USA different aspect of our division mission. Ultimately, the following eight papers were accepted for production.

Susie Gronseth and Waneta Hebert begin our issue with an exploration of using the GroupMe instant messaging platform to facilitate online discussions in an online university course. Her study not only examines the integration of the platform, but it also presents ideas for the appropriate types of activities that might be best served by using a technology such as this one.

Next, Joseph Gaston and Byron Havard investigate how collaborative video production effects the situational interest of elementary school students. Their research demonstrates an influence on how these young learners perceive their own learning, their interest in the content, and how interested they are in school.

Pamela Ponners and Yulia Piller examine how using augmented reality impacts the mental models elementary school students have to describe what a scientist is and does. Their study suggests that while students may initially think scientists work in dark, isolated places, the integration of augmented reality helped alter students' mental models. Students at the end of the study had mental models that imagined scientists as "someone who creates rather than destroys."

Tonia Dousay and Jennifer Weible present a design-based case study on the effect of 3D pens and how they assist in fostering creativity. The study, consisting of three cases with a total of nine students should be particularly interesting to those interested in fostering creative perception and production in the classroom.

John Curry, Sean Jackson and Maria Benchic report the findings of a four-year longitudinal study of a 1:1 implementation of iPads in a rural high school. This study details the implementation plan, and four years of focus groups with students as well as detailed school data. Findings include the need for faculty to receive consistent professional development (beyond the implementation) for the success of the 1:1 initiative.

$\mathrm{Phu} \mathrm{Vu}$, Scott Fredrickson and Martonia Gaskill also report research on a 1:1 implementation, but this time with Chromebooks. The researchers report the need for a clear reason for the 1:1 implementation, the importance of obtaining buy-in from all stakeholders and report similar 
findings to the previous article and emphasize the need for effective professional development activities for the faculty.

Julia Parra, Carolyn Raynor, Azadeh Osanloo and Rene Guillaume reimagine what a learning technologies course should look like. Some of the themes discussed include the pedagogy of caring and love, makerspaces, critical thinking as an essential skill, the need to balance the course organization and technology content, and personal learning networks.

Finally, Tiffany Roman and Jon Racek explore the use of 3D virtual environments, specifically Google Blocks, and how they can improve the learning situation. The researchers discuss the benefits and limitations of 3D modeling tools, and encourage "scholars who are interested in incorporating student use [of these tools] to consider the pedagogical aims of their own teaching and learning contexts, as well as the ways in which culture is embedded and aligned throughout the design process."
On behalf of the membership of the Division of Emerging Learning Technologies, we are grateful for the support we have been given throughout this process. We appreciate the division members who came before us in all previous iterations of this division. They laid the solid foundation for the research and practice we now enjoy. We appreciate AECT and its leadership for the guidance and direction given us through this rebranding process. As guest editors, we appreciate Chuck Hodges, Editor-in-Chief of TechTrends, for his leadership and patience with us as we worked on this issue. Honestly, we would not have been able to do this without him on our side. Finally, we challenge all to not fall prey to the misguided integration of technology simply for technology's sake, and we invite all researchers and practitioners to carefully consider emerging technologies for thoughtful integration into instruction. 